Proc. Indian Acad. Sci. (Earth Planet. Sci.), Vol. 92, Number 1, March 1983, pp. 31-36.

- Printed in India.

\title{
Solar cycle and equatorial stratopause temperature
}

\author{
K MOHANAKUMAR and S DEVANARAYANAN \\ Department of Physics. University of Kerala. Kariavattom. Trivandrum 695 581, India.
}

MS received 22 February 1982; revised 7 October 1982

\begin{abstract}
Variations in a solar activity and their effect if any on the temperature of the stratopause are studied. Monthly mean stratopause temperatures during 1969-1976 and departures from the monthly mean value of eight-year period. determined for four equatorial rocket launching stations, viz. Ascension lsland, Kwajalein. Fort Sherman and Thumba, are statistically compared with sunspot number departures. To study the effects of seasonal variation on stratopause temperature, the data have been divided into winter, summer and equinoctial periods. Seasonwise study indicates that the correlation between the stratopause temperature and sunspot number is positive and just below the significant level for Thumba and positive and highly significant over all the other stations with a better relationship in equinoctial periods than in both winter and summer. The estimated regression coefficients are positive and significant.
\end{abstract}

Keywords. Solar cycle; stratopause temperature; middle atmosphere; correlation coefficient; regression coefficient.

\section{Introduction}

Stratopause is the level of maximum vertical temperature as a consequence of absorption of solar ultraviolet energy by ozone. This level represents the equilibrium altitude, where heat input, capacity and assorted loss mechanism combine to produce the maximum temperature. The temperature variation in this region has been thought to be caused by atmospheric heating produced by energetic particles and electromagnetic radiation from the sun. Heath (1973) indicated that during a solar cycle, the intensity of the solar spectrum may be ennanced by a factor of 2 near $1800 \AA$ and by $20 \%$ near $2900 \AA$ during sunspot maximum. If this is true, according to Fritz and Angell (1976) the stratopause temperature might vary with the sunspot cycle, and they reported a $\sim 20 \%$ stratopause temperature difference during sunspot maximum and minimum (employing the formula $\mathrm{d} T / \mathrm{d} t=-0.214 \mathrm{~T}+49.8^{\circ} \mathrm{K} /$ day). This could be observed in the rocketsonde data.

The present-study is an investigation of a relationship between the stratopause temperature and solar activity, as represented by Zürich sunspot number. The stratopause temperatures have been obtained (World Data Centre A, Meteorology) from monthly mean temperature data of four equatorial rocket launching stations, viz. Ascension Island $\left(8^{\circ} \mathrm{S}, 14^{\circ} \mathrm{W}\right)$, Kwajalein $\left(9^{\circ} \mathrm{N}, 168^{\circ} \mathrm{E}\right)$, Fort $\operatorname{Sherman}\left(9^{\circ} \mathrm{N}, 80^{\circ} \mathrm{W}\right)$ during 1969-76 and Thumba $\left(8^{\circ} \mathrm{N}, 77^{\circ} \mathrm{E}\right)$ during December 1970-1976. These four stations are quite well spaced and distributed over the equatorial region of the globe.

\section{Data and method of analysis}

Stratopause mean temperatures for each month were listed after computation from the HAMR (high altitude meteorological rocket) data (World Data Centre A, Meteorol- 
ogy) and the departures from the monthly mean value obtained from data for the period 1969-1976 for each month. The sunspot numbers for the same period were then taken (Solar and Geophysical Data 1971, 1977) and their departures from the mean $(1969-1976$ mean $=55.1)$ were estimated. Finally, a possible correlation coefficient between the two variables, viz. stratopause temperature and sunspot number, was found by using a standard statistical method.

In order to find the significance of the estimated correlation coefficient $R$ between temperature of stratopause and sunspot number, the results were treated with the student's $t$ test. Accordingly, the correlation is significant only if the calculated value is greater than the tabular value above at $95 \%$ level of significance.

Since $R$ is only a measure of the degree of relationship between the stratopause temperature and the sunspot number one has to resort to regression analysis to establish the nature of the relationship, delineating the cause and effect. The regression coefficient of stratopause temperature on sunspot number is

$$
B_{T Z}=\frac{\sum_{i=1}^{N} T_{i} Z_{i}}{\sum_{i=1}^{N} Z_{i}^{2}}
$$

where $T_{1}=$ departure of temperature from the mean, $Z_{1}=$ departure of sunspot number from the mean and $B_{T Z}$ is represented by the slope of the regression line.

The correlation coefficient, regression coefficient and the value of $N$ used, listed in table 1, were calculated for the seasons summer (May to August), winter (November to February) and the two equinoctial periods (March-April and September-October) in the case of the stations located in the northern hemisphere, and for Ascension Island, a southern hemispheric station, where the summer and winter seasons are just opposite to those of the northern hemisphere.

\section{Results and discussion}

The monthly departures of sunspot number from 55.1 (the 8 year, i.e. 1969-1976 mean value) were plotted against time and is shown in figure 1.1969 was the year of sunspot maximum and 1976 was the year of sunspot minimum.

The deviations of stratopause temperature from the 8-year mean monthly value for the four stations are also graphically presented in figure 1 . As the active sun becomes quiet the stratopause temperature deviations change from positive to negative values, which is a common trend seen over the four stations. Nearly quasi-biennial oscillation ( 26 to 32 months periodicity) are present in the temperature data at all the stations after 1972. These oscillations are present in the sunspot number as well. As these oscillations are not in phase at all the stations this may explain in part the variation of the correlation coefficient from station to station resulting in poor values of $R$ over Thumba. It is also possible that the solar activity effects appear with a delay as is evident from the work by Rajaram et al (1979). who found that the tropopause height at the equatorial station was correlated with the sunspot activity with a lag of three years. It is possible that the correlations over Thumba improve if a lag is introduced with respect to solar activity, i.e. the temperature series is correlated to the sunspot series shifted backwards by one, two or three years. 


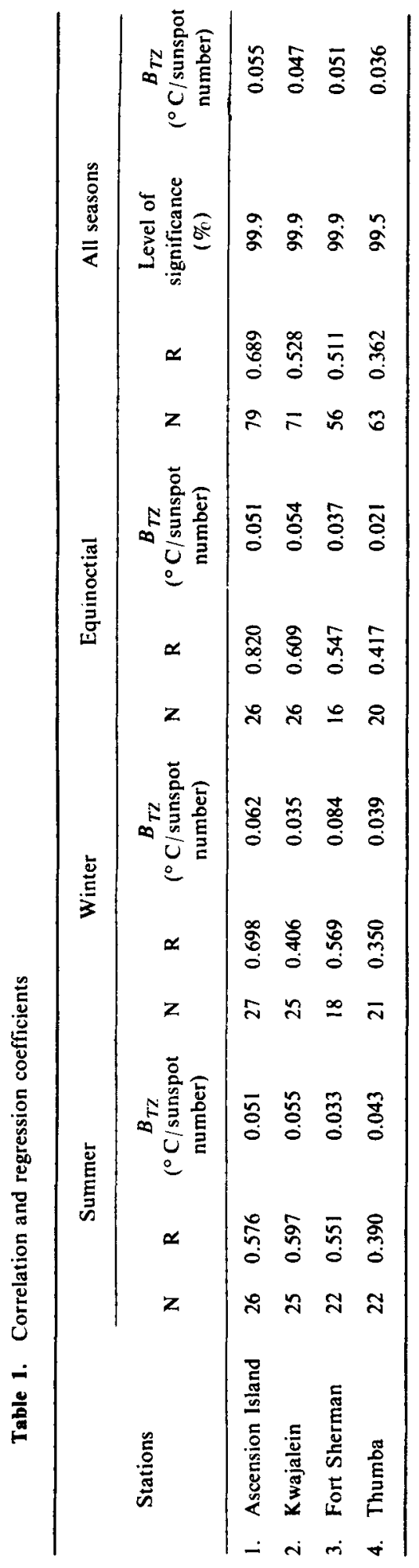




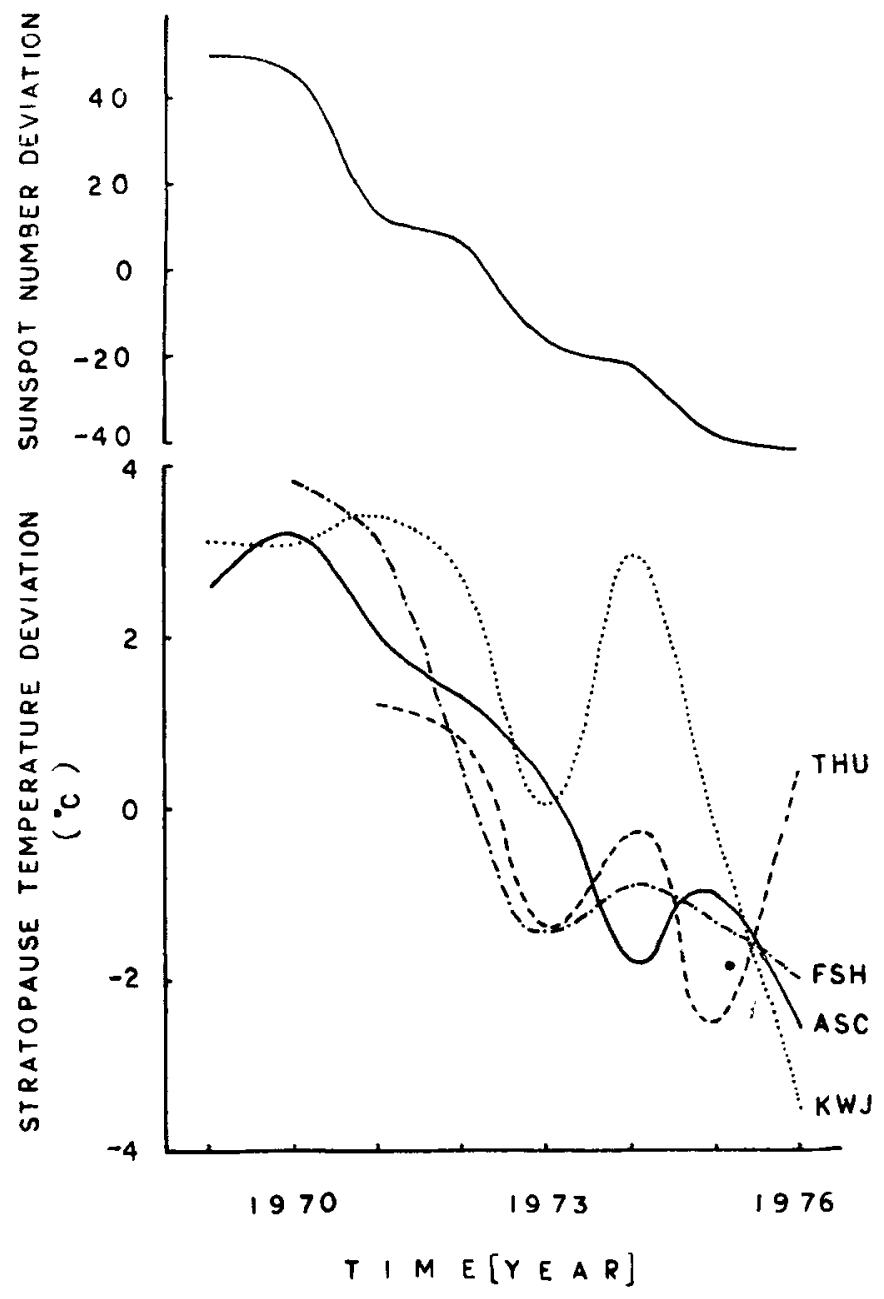

Figure 1. Variation of sunspot number departure and stratopause temperature departure from the respective 8-year mean, with time. (ASC-Ascension Island, KWJ-Kwajalein, FSH - Fort Sherman, THU - Thumba)

The statistical study, on the other hand, reveals that there exists a (positive) correlation (significance well above $95 \%$ ) between the stratopause temperature and sunspot number for each season in all the stations except Thumba. It is also evident from table 1 that the correlations are higher during the equinoctial periods. The estimated correlation coefficients for all the seasons over Ascension Island, Kwajalein and Fort Sherman are of such magnitude that the correlation between stratopause temperature and sunspot number are highly significant (as the level of significance is above $99.9 \%$ ) in the stratopause. The correlation over Thumba for all the seasons is also significant (above $99.5 \%$ level). The highest correlation (0.82) is over Ascension Island displayed during equinoctial periods, and Thumba has the lowest value (0.35) during winter. The influence of seasons on the correlation coefficient is the lowest over Fort Sherman. 
The regression coefficient of stratopause temperature on sunspot number is higher in the western hemispheric stations than in the eastern hemispheric station, viz. Thumba.

During the period of sunspot maximum, increased amounts of ultraviolet radiation enter the atmosphere. These radiations are absorbed by the ozone present in the stratosphere causing an increase in the temperature of the stratosphere. Thus a higher temperature can be observed in the stratopause (Webb 1966). It is well-known that the diurnal variations observed in the stratosphere have a greater amplitude in the upper stratosphere, especially in the stratopause. A diurnal temperature variation of $\sim 4^{\circ} \mathrm{K}$ is present at stratopause because heating due to ozone absorption occurs only during the day time, whereas cooling due to the emission from carbon dioxide takes place all the time (Houghton 1977). This might form a basis to explain the observations over Thumba related with the post-sunset rocket launching.

Fritz and Angell (1976) suggested that the temperature change in the tropical stratopause seems to have its greatest amplitude at the equator and to have long duration and widespread aerial extent. From the analysis of Angell and Korshower (1978) of the high altitude meteorological rocket data over ten stations for all seasons for the period $1965-1977$, a $6^{\circ} \mathrm{C}$ lowering for summer in the layer $46-55 \mathrm{~km}$ is found when the nearly active sun becomes quiet. The combined station data involving all seasons and a three-year smoothing yield a temperature decrease of about $4^{\circ} \mathrm{C}$ in this layer from solar maximum to minimum.

Quiroz (1979) investigated temperature at two discrete levels, 35 and $50 \mathrm{~km}$. for the period 1965-1977 for seven stations lying in the latitude $8^{\circ} \mathrm{S}-64^{\circ} \mathrm{N}$ with solar cycle 20 . $\mathrm{His}$ investigation yielded overall coefficients of correlation in the range +0.7 to +0.9 between upper stratospheric temperature and sunspot number. He found a decrease of the average temperature from solar maximum to minimum for summer which is $4^{\circ} \mathrm{C}$ at $50 \mathrm{~km}$. A theoretical analysis by Callis and Nealy (1978), assuming an approximately $20 \%$ increase in the uv radiation during sunspot maximum, resulted in a temperature increase of about $15^{\circ} \mathrm{C}$ in the $40-50 \mathrm{~km}$ at this time.

A high significant correlation over stations in the western hemisphere and insignificant negative correlation over Thumba have been reported earlier (Mohanakumar and Devanarayanan 1982) and this anomaly was not explained. But the present study attributes the anomaly over Thumba to the presence of waves over the station (figure 1). During the sunspot minimum year 1976, Thumba alone displayed a sudden rise in temperature. This higher stratopause temperature actually led to the estimated correlation to be insignificant and negative whereas it was found to be significant and positive over the western hemispheric stations.

\section{Conclusion}

Our study on the rocketsonde data at the four equatorial meteorological rocket launching stations showed that the stratopause temperature is influenced by the sunspot cycle. The effect is more prominent during the equinoctial periods. Correlation that exists for all seasons over Ascension Island, Kwajalein, Fort Sherman was found to be highly significant. A wavy pattern is observed in the stratopause temperature over both Thumba and Kwajalein. The positive, significant values of both the correlation and regression coefficients found over all these stations indicate a relation existing between the solar cycle and the equatorial stratopause temperature. 


\section{Acknowledgements}

The authors thank Dr V Narayanan of Vikram Sarabhai Space Centre, Trivandrum for assistance in the meteorological rocket data used here. They thank the referees for valuable comments and suggestions. One of them (KM) thanks the UGC for awarding a fellowship.

\section{References}

Angell J K and Korshower J 1978 J. Atmos. Sci. 351758

Callis L B and Nealy J E 1978 Geophys. Res. Lett. 5249

Fritz S and Angell J K 1976 J. Geophys. Res. 811051

Heath D F $1973 J$ Geophys. Res. 782779

Houghton J T 1977 Physics of Atmospheres (London: Cambridge Univ. Press)

Mohanakumar K and Devanarayanan S 1982 Mausam 33405

Quiroz R S 1979 J. Geophys. Res. 841979

Rajaram M, Singh B P and Gupta H V 1979 Tellus 31515

Webb W L 1966 Structure of the Stratosphere and mesosphere (New York: Academic Press) 